УДК 631.16:658.155:332.2

$10.17213 / 2075-2067-2020-3-38-48$

\title{
МОНИТОРИНГ РИСКОВ ИНВЕСТИЦИОННЫХ МЕЛИОРАТИВНЫХ ПРОЕКТОВ
}

\author{
(С) 2020 г. И. Ф. Юрченко*, И. П. Бандурина **, И. И. Сальникова ** \\ *Всероссийский научно-исследовательский институт гидротехники и мелиорации \\ имени А. Н. Костякова, г. Москва, Россия \\ **Южно-Российский государственный политехнический университет (НПИ) \\ имени М. И. Платова, г. Новочеркасск, Россия
}

Целью исследования является совершенствование нормативно-методической базы оценки эколого-экономической эффективности мероприятий мелиоративных инвестиционных проектов.

Методологическую базу исследования представляет метод Монте-Карло, соответствующий международным стандартам, теории и алгоритмам инновачионных способов определения рисков, а также возможность предоставления пользователю информации о содержательной части операций оценки риска и обеспечение учета его предпочтений в проиессе выполнения расчетов. К настоящему времени разработано немало инструментариев для автоматизачии прочедур анализа рисков, в том числе и выполняемых методом МонтеКарло, которые с разной степенью полноты охарактеризованы в различных исследованиях.

Результаты исследования. Выполнен анализ приоритетных методов оценки рисков недостижения прогнозируемых экономических показателей проектных решений и показана перспективность метода имитационного моделирования (метода Монте-Карло) для практического использования в сфере мелиорации. Представлены результаты оценки риска эколого-экономической эффективности противофильтрационных покрытий гидротехнических сооружений оросительных систем, выполненной методом Монте-Карло в среде программного продукта Crystal Ball, и установлена необходимость повыщения надежности прогнозируемых результатов действенности проектируемых мероприятий.

Перспективу исследования составляет оиенка риска доходности проектируемых мероприятий, которая способствует развитию действующей и становлению новой теории обоснования целесообразности реализаџии мероприятий мелиоративных инвестиционных проектов.

Ключевые слова: мониторинг; риск; инвестиционные мелиоративные проектыл.

\section{RISK MONITORING OF INVESTMENT MELIORATIVE PROJECTS}

\author{
(C) 2020 I. F. Yurchenko*, I. P. Bandurina**, I. I. Salnikova** \\ *All-Russian Research Institute of Hydraulic Engineering and Land Reclamation \\ named after A. N. Kostyakov, Moscow, Russia \\ **Platov South Russian State Polytechnic University (NPI), Novocherkassk, Russia
}

The purpose of the study is to improve the regulatory and methodological framework for assessing the environmental and economic effectiveness of measures for reclamation investment projects. 
The methodological base of the study is presented by the Monte Carlo method, which corresponds to international standards, theory and algorithms of innovative methods for determining risks, as well as the ability to provide the user with information about the content of risk assessment operations and ensuring that their preferences are taken into account in the calculation process. To date, many tools have been developed to automate risk analysis procedures, including those performed by the Monte Carlo method, which have been characterized in various studies with varying degrees of completeness.

The results of the study. The analysis of priority methods for assessing risks of not achieving the predicted economic indicators of design decisions is carried out and the prospects of the simulation method (Monte Carlo method) for practical use in the field of land reclamation are shown. The results of the risk assessment of the environmental and economic efficiency of antifilter coatings of hydraulic structures of irrigation systems, performed by the Monte Carlo method in the Crystal Ball software environment, are presented, and the need to increase the reliability of the predicted results of the effectiveness of the designed measures is established.

The prospect of the study is the risk assessment of the profitability of the designed measures contributes to the development of the current and the establishment of a new theory of justification of the feasibility of the implementation of reclamation investment projects.

Key words: monitoring; risk; investment reclamation projects.

Введение. Оценка действенности мелиоративных инвестиционных проектов (МИП) отличается высоким уровнем риска прогнозируемых эколого-экономических показателей из-за длительной, превышающей пятидесятилетний период реализации проектных решений, большого временного блага от вложения средств до отдачи [10]. Успешность снижения риска МИП в значительной мере обусловлена использующимися методами анализа действенности проектируемых решений, существенно различающихся учетом изменчивости (в пространстве и времени) параметров эффективности проекта, формирующих количественные показатели риска [3].

Обзор научно-исследовательской литературы. Отсутствие в экономической теории и практике МИП унифицированного способа действенности проектных решений, однозначно удовлетворяющего многосторонним требованиям пользователя к анализу риска инвестиционных вложений, обусловили приоритеты эвристических моделей, использующих навыки управленцев. Максимальное развитие получили количественные (аналитические), качественные и вероятностные методы расчета, отличающи- еся каждый своим преимуществом и недочетом [18], без явного права предпочтения. Практикующиеся способы анализа и учета рисков инвестпроектов и сравнительный анализ их функциональных возможностей представлен на рисунке 1 по исследованиям [14]. Указанные способы делятся на: качественные, оценивающие риск по определенной шкале (уровень риска высокий, средний, низкий), количественные, оценивающие риски по числовому значению показателя, и смешанные.

Качественный анализ выполняется для обнаружения и характеристики вероятных рисков инвестиционных решений, вскрытия причин и условий воздействия на них, определения ущерба от ожидаемых рисков и стоимости мероприятий его сокращения и/или устранения [17]. Этот подход, как правило, предваряет выполнение количественного мониторинга характеристик риска инвестиционных решений.

Общепризнанный приоритет количественного учета рисков и неопределенности инвестиционных решений объясняется применением методов, повышающих точность исчисления возможных потерь и сводящих к минимуму субъективность восприятия ситуации лицом, принимающим решение [11]. 
Наличие множества способов контроля, учета и прогноза рисков МИП не стало гарантией легкости в практике оценки действенности последних [2]. Это связано:

- с большим размахом требований к учету действенности конкретных МИП;

- с недостаточным вниманием к специфике МИП при выборе способа оценки риска, как правило, обусловленного предпочтениями разработчика и хозяйствующего субъекта;

- с отсутствием дифференцированного подхода к оценке риска МИП в зависимости от стадии его жизненного цикла;

- с замещением оценки риска оценкой неопределенности случайных событий;

- с отсутствием должной унификации определенных способов оценки риска;
- со сложностью расчетов и использования параметров конкретного проекта в теоретических моделях.

Вместе с тем прослеживается приоритет методов чувствительности, сценарного и имитационного моделирования.

Относительное лидирование статистического метода мониторинга риска ИП объясняется доступностью применяемых теоретических подходов пониманию управленцев, формирующих решение, и простотой вычислений [12]. Критериями учета и анализа риска являются средние значения случайным образом изменяющихся показателей эффективности инвестиционных решений и их вариация, характеризующая степень отклонения прогнозируемого значения от среднего.

\begin{tabular}{|c|c|c|c|}
\hline \multicolumn{4}{|c|}{ МЕТОДЫ КОНТРОЛЯ, УЧЕТА И ПРОГНОЗА РИСКА ИП } \\
\hline Качественные методы & $\begin{array}{c}\text { Простота } \\
\text { реализации }\end{array}$ & Достоверность & $\begin{array}{l}\text { Динамика } \\
\text { реализации }\end{array}$ \\
\hline Экспертный & + & + & + \\
\hline Рейтинговый & + & + & + \\
\hline Метод аналогий & + & + & + \\
\hline $\begin{array}{c}\text { Контрольных перечней } \\
\text { источников риска }\end{array}$ & + & + & - \\
\hline Статистические методы & + & & + \\
\hline \multicolumn{4}{|c|}{ Аналитические методы } \\
\hline Анализ чувствительности & - & + & + \\
\hline $\begin{array}{c}\text { Регулирование нормы } \\
\text { дисконта }\end{array}$ & + & - & + \\
\hline $\begin{array}{c}\text { Достижение точки } \\
\text { безубыточности }\end{array}$ & + & + & - \\
\hline Сценарный анализ & - & - & + \\
\hline Дерево решений & + & - & - \\
\hline $\begin{array}{c}\text { Имитационное } \\
\text { моделирование } \\
\text { (метод Монте-Карло) }\end{array}$ & - & + & + \\
\hline Количественные методы & $\begin{array}{c}\text { Простота } \\
\text { реализации }\end{array}$ & Достоверность & $\begin{array}{l}\text { Реализация } \\
\text { в динамике }\end{array}$ \\
\hline
\end{tabular}

Рис. 1. Способы контроля, учета и прогноза риска инвестиционных проектов 
Лучшие решения соответствуют меньшей вариации оцениваемого параметра. Преимущества анализа риска статистическим методом часто снижаются отсутствием фактических сведений о законе распределения вероятности оцениваемого показателя и замене его в большинстве случаев нормальным, что не способствует точности получаемого результата. Выполнение мониторинга требует данных длительных рядов наблюдений за параметрами эффективности инвестиционных решений, что также не всегда достижимо.

К достоинствам метода варьирования параметров (анализа чувствительности) относится высокая теоретическая обоснованность, простота расчетов, возможность визуализации результата и т.п. свойства. Недостатки метода - невозможность учета корреляции между факторами риска и получения вероятностного распределения оценок риска. Доходность МИП наиболее зависима от ставки дисконтирования. Это связано с экспоненциальной зависимостью прогнозируемой стоимости денег от данного фактора, при фиксированной ставке дисконтирования приоритет получают закупочные цены и издержки сельскохозяйственного производства [8].

Сценарный анализ, являясь логическим развитием анализа чувствительности, повышает точность расчетов и, соответственно, результирующие данные, обеспечивает учет вариабельности событий для оценочных показателей действенности проекта. Оценка выполняется по оптимистическому, пессимистическому и наиболее вероятному сценариям одновременно изменяющихся факторов, при которых рассчитываются оценочные показатели действенности проекта. Риск оценивается по отклонению средневзвешенного из значений оптимистического, пессимистического и оптимального вариантов доходности МИП от значения базового варианта. По различию запланированных и прогнозных значений показателей эффективности инвестиций в проект делаются выводы о риске инвестиционных решений и/или о наличии в проекте дополнительных факторов риска, подлежащих учету. К недостаткам метода следует отнести отсутствие формальных способов формирования границ сценариев и оценок значений переменных для них [6].
Достоинства метода Монте-Карло - соответствие международным стандартам, теории и алгоритмам инновационных способов определения рисков, предоставление пользователю информации о содержательной части операций оценки риска и обеспечение учета его предпочтений в процесс расчетов [4].

Методология исследования. Широкому использованию метода Монте-Карло в практике мониторинга риска проектных решений изначально препятствовали сложность и трудоемкость расчетов, которые по мере развития информационных технологий утрачивают свое значение.

К настоящему времени разработано немало инструментариев для автоматизации процедур анализа рисков, в том числе и выполняемых методом Монте-Карло, которые с разной степенью полноты охарактеризованы в исследованиях $[7,16]$.

По результатам анализа действующих подходов к развитию системы оценки эффективности МИП для становления практики анализа и учета рисков их доходности предлагается инструментарий Crystal Ball, paзработанный корпорацией Oracle [9].

В настоящей публикации процедуры анализа и учета риска эколого-экономической действенности МИП методом имитационного моделирования (метод Монте-Карло) представлены на примере действующего проекта, ориентированного на повышение устойчивости и снижение непроизводительных трат поливной воды, разработанного и реализованного сотрудниками ОАО «Институт безопасности гидротехнических сооружений» [1].

Критерием экономической действенности МИП принято положительное значение дисконтированного приростного чистого дохода (ЧДД $>0)$, который определялся по дисконтированному сальдо приростного чистого денежного потока. В качестве эффекта (результата МИП) принят предотвращенный ущерб от ликвидации несанкционированных затрат поливной воды, в качестве затрат стоимость создания и эксплуатации защитного устройства (таблица 1).

Продление периода действенной эксплуатации сооружений оросительных систем обеспечивается устройством противофиль- 
трационного двухслойного покрытия оросительных каналов из геотекстильного материала с грунтовым заполнителем [13].

Дисконтированное сальдо приростного потока, рассчитанное за нормативный период эксплуатации защитного комплекса гидротехнического сооружения, положительно и составляет 210,6 тыс. руб., срок окупаемости совокупных капитальных вложений по приросту дисконтированного чистого дохода не превышает полутора лет.

Риск МИП рассчитывался по вероятности недостижения планируемой доходности при отклонении от прогнозируемых значений пре-

\section{Данные для расчета действенности противофильтрационной защиты}

Таблица 1

\begin{tabular}{|c|c|c|c|}
\hline \multirow{2}{*}{ Наименование } & \multirow{2}{*}{ Ед. измерения } & \multicolumn{2}{|c|}{ Данные } \\
\hline & & до ремонта & после ремонта \\
\hline Сокращение потерь воды* & 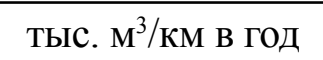 & - & 92,5 \\
\hline Удельные издержки на водоподачу* & pyб./ $\mathrm{M}^{3}$ & 0,12 & 0,12 \\
\hline $\begin{array}{l}\text { Предотвращённый ущерб от сокращения по- } \\
\text { терь поливной воды }\end{array}$ & тыс. руб./ в год & - & 11,1 \\
\hline Стоимость защитного устройства & тыс. руб./км & - & 50 \\
\hline $\begin{array}{l}\text { Эксплуатационные затраты противофильтра- } \\
\text { ционной защиты }\end{array}$ & тыс. руб./км в год & - & $1,0^{*}$ \\
\hline Срок службы защитного устройства & год & & 30 \\
\hline Норма дисконта & $\%$ & & 8 \\
\hline
\end{tabular}

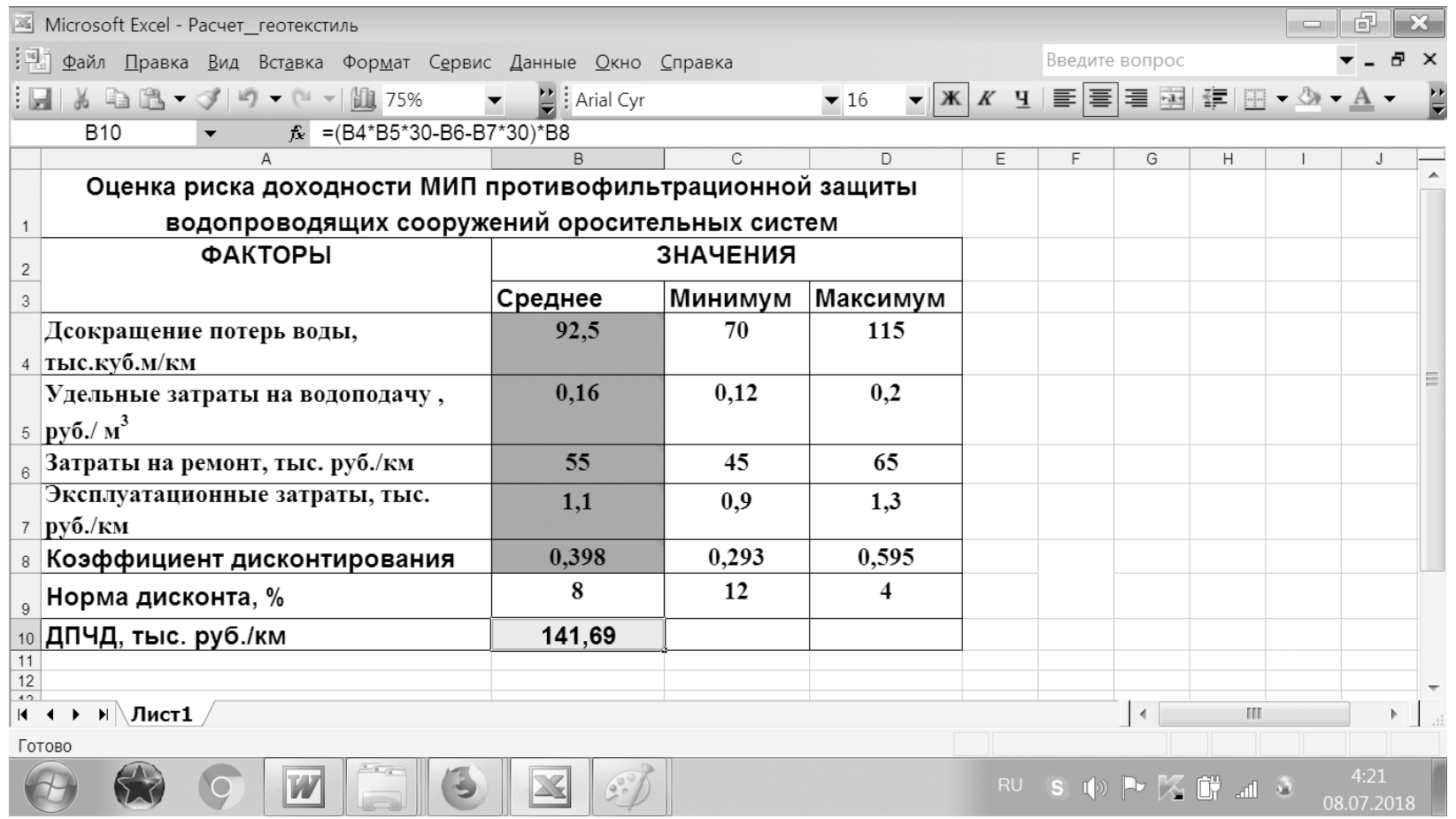

Рис. 2. Вид аналитической зависимости доходности от реализации комплекса противофильтрационной защиты 
дотвращенного ущерба от сокращения потерь воды, издержек на устройство и эксплуатацию защитного устройства и нормы дисконта. Эти факторы являются значимыми при расчетах доходности МИП [5]. Расчеты выполнены с использованием коммерческого программного продукта Crystal Ball в среде Excel.

Оценка риска МИП потребовала:

- разработки аналитической зависимости экономической эффективности проекта от определяющих ее факторов;

- формирования функций распределения для зависимости экономической эффективности МИП и определяющих ее факторов;

- компьютерного генерирования случайных значений эффективных факторов аналитической зависимости; МИП;

- расчета параметров риска доходности

- анализа итоговых результатов.

На рисунке 2 представлены для реализации в программном комплексе Crystal Ball: аналитическая зависимость (1) для вычисления доходности от внедрения комплекса противофильтрационной защиты (ячейка B10), перечень значимых факторов (ячейки A4-A8), их средние, максимальные и минимальные значения (ячейки (B4-B8), (D4-D8), (C4-C8) соответственно).

Зависимость для вычисления доходности от внедрения комплекса противофильтрационной защиты (Д) имеет вид:

$$
\text { Д }=(\mathrm{C \Pi} \cdot 3 \mathrm{~B} \cdot \mathrm{T}-\mathrm{P}-Э 3 \cdot \mathrm{T}) \cdot \mathrm{K},
$$

где СП - сокращение потерь воды, тыс. $^{3} / к м$ в год; ЗВ - удельные затраты на водоподачу, руб/ $\mathrm{M}^{3} ;$ Р - затраты на ремонт, тыс. руб./км; Э3 - эксплуатационные затраты, тыс. руб./км в год; Т - срок службы защитного сооружения, год; К - коэффициент дисконта.

Вероятность прогнозируемых значений параметров и зависимости доходности МИП характеризуется функциями нормального распределения, для описания которых достаточно знания среднего значения и стандартного отклонения от среднего.

Результаты исследования. Результаты расчета параметров функций распределения для ключевых факторов зависимости доходности МИП представлены в таблице 2.

Итоговый результат оценки риска МИП представлен на графике рисунка 3. О низком риске эффективности МИП свидетельствует стопроцентная вероятность положительного значения действенности инвестиционного проекта (Д>0).

Но вместе с тем, очевидно, что вероятность доходности в размере 210,6 тыс. руб., заявленной в проекте, не достигает $10 \%$, что ниже среднего значения [15]. Следовательно, необходимо повышенное внимание к реализации производственных процессов и технологий, регла-

Параметры функций распределения

Таблица 2

\begin{tabular}{|c|c|c|c|}
\hline Фактор & $\begin{array}{c}\text { Границы } \\
\text { 90\%-го } \\
\text { доверительного } \\
\text { интервала }\end{array}$ & $\begin{array}{c}\text { Среднее } \\
\text { значение }\end{array}$ & $\begin{array}{c}\text { Стандартное } \\
\text { отклонение } \\
\text { от среднего } \\
\text { значения }\end{array}$ \\
\hline Сокращение потерь воды (СП), тыс. м³/км в год & от 70 до 115 & 92,5 & 13,68 \\
\hline Удельные издержки на водоподачу (ЗВ), руб./м³ & от 0,12 до 0,20 & 0,16 & 0,024 \\
\hline Затраты на устройство защиты (Р), тыс. руб./км & от 65 до 45 & 55 & 6,069 \\
\hline $\begin{array}{l}\text { Эксплуатационные издержки (ЭЗ), тыс. руб./км } \\
\text { в год }\end{array}$ & от 1,3 до 0,9 & 1,1 & 0,122 \\
\hline Коэффициент дисконта (К), \% & от 0,29 до 0,51 & 0,4 & 0,092 \\
\hline $\begin{array}{l}\text { Срок службы противофильтрационной защиты } \\
\text { (Т), год }\end{array}$ & \multicolumn{3}{|c|}{30} \\
\hline Доходность МИП (Д), тыс. руб./км & \multicolumn{3}{|c|}{$Д=(\Pi В \cdot 3 В \cdot T-(3 P+Э 3 \cdot T)) \cdot K$} \\
\hline
\end{tabular}




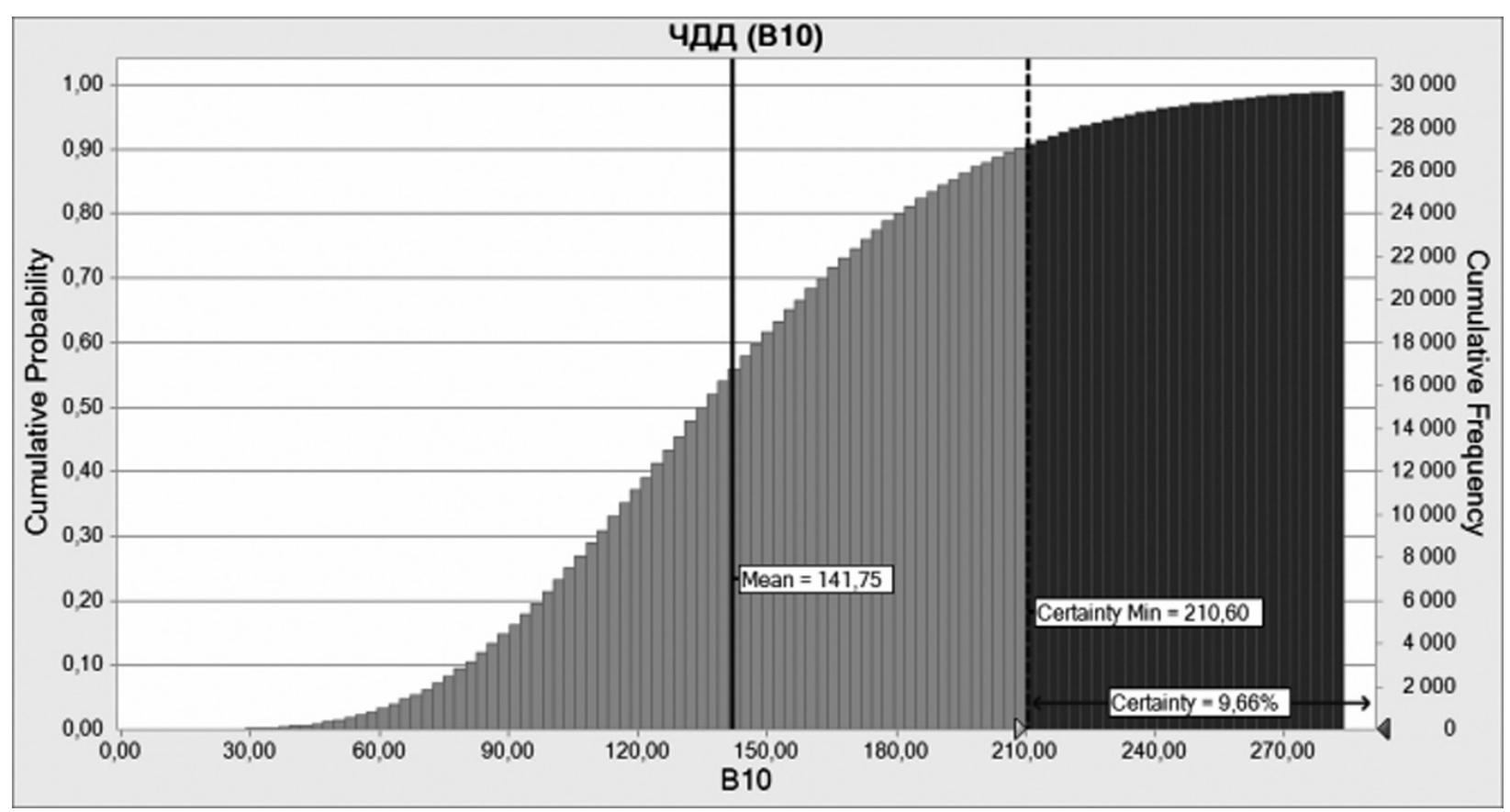

Рис. 3. Результаты моделирования: распределение доходности МИП

ментированных проектом, а также к рыночной конъюнктуре как к приоритетным факторам, определяющим изменчивость результата.

Заключение. Повышение надежности прогнозируемой социально-эколого-экономической результативности МИП требует совершенствования нормативно-правовой базы оценки риска недостижения прогнозируемого результата. В качестве перспективного метода мониторинга действенности МИП предлагается имитационное моделирование или метод Монте-Карло, успешно апробированный в составе настоящих исследований.

\section{Литература}

1. Бандурина И.П. Социальный капитал и социальный контроль в экономике России: роль экологических организаций // Вестник Южно-Российского государственного технического университета (НПИ). Серия: Социально-экономические науки. - 2011. №3. - С. 293-299.

2. Бандурина И.П., С Сальникова И.И., Бандурин М. А. Определение уровня влияния рисков на эффективность инвестиционных проектов в АПК // Вестник Южно-Российского государственного технического универ- ситета (НПИ). Серия: Социально-экономические науки. - 2019. - №6. - С. 19-26.

3. Безопасность бесхозяйных гидротехнических сооружений / Г.Т. Балакай, И. Ф. Юрченко, Е.А. Лентяева, Г.Х. Ялалова. - Германия: LAP Lambert, 2016. - 85 c.

4. Бесфалильная Е.В., Бандурина И.П. Совершенствование методов развития рециклинговых технологий утилизации промышленных и бытовых отходов // Инженерный вестник Дона. - 2015. - №2-2 (36). - С. 57.

5. Бесфамильная Е.В., Бандурина И.П. Совершенствование системы обращения с отходами производства и потребления как социально-экономическая и экологическая необходимость // Вестник Южно-Российского государственного технического университета (НПИ). Серия: Социально-экономические науки. - 2015. - №4. - С. 100-109.

6. Волосухин Я. В., Бандурин М. А. Вопросы моделирования технического состояния водопроводящих каналов при проведении эксплуатационного мониторинга // Мониторинг. Наука и безопасность. - 2012. №1. - С. 70-74.

7. Волосухин Я.В., Бандурин М.А. Проведение эксплуатационного мониторинга c применением неразрушающих методов контроля и автоматизация моделирования 
технического состояния гидротехнических сооружений // Мониторинг. Наука и безопасность. - 2011. - №3. - С. 88-93.

8. Мукаев Р.Х. Оценка рисков инвестиционных проектов разработки нефтяных месторождений методом имитационного моделирования (Монте-Карло) // Тенденции и перспективы развития науки XXI века. 2015. — №1. - С. 64.

9. Научные основы создания и управления мелиоративными системами в России / Под редакцией Л.В. Кирейчевой. - М: «ФГБНУ ВНИИ агрохимии», 2017. — 296 с.

10. Новые технологии проектирования, обоснования строительства, эксплуатации и управления мелиоративными системами/ Под редакцией доктора технических наук, профессора Л.В. Кирейчевой. — М., 2010. — $240 \mathrm{c}$.

11. Повышение ответственности сельхозтоваропроизводителей за воспроизводство почвенного плодородия мелиорируемых земель / Г. Т. Балакай, И. Ф. Юрченко, Е. А. Лентяева, Г.Х. Ялалова // Агрохимический вестник. - 2015. - Т. 2. - №2. - С. 29-33.

12. Санникова М.О., Ярославский В.А. Теоретические основы процесса оценки рисков мелиоративных инвестиционных проектов // Вестник Саратовского государственного социально-экономического университета. - 2012. - №5 (44). - С. 136-140.

13. Способ проведения эксплуатационного мониторинга технического состояния лотковых каналов оросительных систем: пат. 2368730 Рос. Федерация: МПК Е 02 В 13/00/ Волосухин В.А., Бандурин М. А.; заявитель и патентообладатель Новочерк. гос. мелиор. акад. №2008100926/03, заявл. 09.01.08; опубл. 12.09 .08 , Бюл. №28. - 7 c.

14. Турмачев E.C. Методические проблемы количественного определения рисков инвестиционных проектов // Анализ эффективности инвестиций. - 2006. - №3. - С. 45-58.

15. Юрченко И. Ф. Методологические основы создания информационной системы управления водопользованием на орошении// Вестник российской сельскохозяйственной науки. - 2017. - №1. - С. 13-17.

16. Юрченко И. Ф. Планово-предупредительные мероприятия повышения надежности мелиоративных объектов // Природообустройство. - 2017. - №1. - С. 73-79.
17. Юрченко И. Ф., Носов А.К. Эффективность организационно-правовых форм использования мелиорируемых земель // Вестник РАCXН. - 2012. - №6. - C. 10-12.

18. Risk assessment of land reclamation investment projects / I.F. Yurchenko, M.A. Bandurin, V.V. Vanzha and other // Advances in social science, education and humanities research Proceedings of the International Conference Communicative Strategies of Information Society (CSIS 2018). - 2019. - Pp. 216-221.

\section{Reference}

1. Bandurina I.P. Sotsial'nyy kapital i sotsial'nyy kontrol' v ekonomike Rossii: rol' ekologicheskikh organizatsiy [Social capital and social control in the Russian economy: the role of environmental organizations] // Vestnik Yuzhno-Rossiyskogo gosudarstvennogo tekhnicheskogo universiteta (NPI). Seriya: Sotsial'no-ekonomicheskie nauki [Bulletin of the South Russian state technical University (NPI). Series: Socio-economic Sciences]. — 2011. — №3. — Pp. 293-299.

2. Bandurina I.P., Sal'nikova I. I., Bandurin M.A. Opredelenie urovnya vliyaniya riskov na effektivnost' investitsionnykh proektov v APK [Determining the level of risk influence on the effectiveness of investment projects in the agro-industrial complex] // Vestnik Yuzhno-Rossiyskogo gosudarstvennogo tekhnicheskogo universiteta (NPI). Seriya: Sotsial'no-ekonomicheskie nauki [Bulletin of the South Russian state technical University (NPI). Series: Social and economic Sciences]. — 2019. — №6. - Pp. 19-26.

3. Bezopasnost' beskhozyaynykh gidrotekhnicheskikh sooruzheniy [Safety of ownerless hydraulic structures] / G.T. Balakay, I.F. Yurchenko, E.A. Lentyaeva, G. Kh. Yalalova. - Germany: LAP Lambert, 2016. - 85 p.

4. Besfamil'naya E. V., Bandurina I. P. Sovershenstvovanie metodov razvitiya retsiklingovykh tekhnologiy utilizatsii promyshlennykh i bytovykh otkhodov [Improving methods for developing recycling technologies for industrial and household waste disposal] // Inzhenernyy vestnik Dona [Don's engineering Bulletin]. 2015. 一 №2-2 (36). - P. 57.

5. Besfamil'naya E. V., Bandurina I.P. Sovershenstvovanie sistemy obrashcheniya s otkhodami proizvodstva i potrebleniya kak sotsial'noekonomicheskaya i ekologicheskaya neobkhodi- 
most' [Improving the system of waste management of production and consumption as a socio-economic and environmental necessity]// Vestnik Yuzhno-Rossiyskogo gosudarstvennogo tekhnicheskogo universiteta (NPI). Seriya: Sotsial'no-ekonomicheskie nauki [Bulletin of the South Russian state technical University (NPI). Series: Social and economic Sciences]. 2015. - №4. - Pp. 100-109.

6. Volosukhin Ya. V., Bandurin M.A. Voprosy modelirovaniya tekhnicheskogo sostoyaniya vodoprovodyashchikh kanalov pri provedenii ekspluatatsionnogo monitoringa [Issues of modeling the technical condition of water supply channels during operational monitoring] // Monitoring. Nauka i bezopasnost' [Monitoring. Science and security]. - 2012. — №1. - Pp. 70-74.

7. Volosukhin Ya. V., Bandurin M.A. Provedenie ekspluatatsionnogo monitoringa s primeneniem nerazrushayushchikh metodov kontrolya i avtomatizatsiya modelirovaniya tekhnicheskogo sostoyaniya gidrotekhnicheskikh sooruzheniy [Conducting operational monitoring using non-destructive methods of control and automation of modeling the technical condition of hydraulic structures] // Monitoring. Nauka i bezopasnost' [Monitoring. Science and security]. — 2011. №3. - Pp. 88-93.

8. Mukaev R. Kh. Otsenka riskov investitsionnykh proektov razrabotki neftyanykh mestorozhdeniy metodom imitatsionnogo modelirovaniya (Monte-Karlo) [Risk assessment of investment projects for oil field development using simulation modeling (Monte Carlo)] // Tendentsii i perspektivy razvitiya nauki XXI veka [Trends and prospects for the development of science in the XXI century]. - 2015. - №1. - P. 64.

9. Nauchnye osnovy sozdaniya i upravleniya meliorativnymi sistemami v Rossii [Scientific basis for the creation and management of irrigation and drainage systems in Russia] / In L. V. Kireycheva (ed). - Moscow: «FGBNU VNII agrokhimii», 2017. - $296 \mathrm{p}$.

10 . Novye tekhnologii proektirovaniya, obosnovaniya stroitel'stva, ekspluatatsii i upravleniya meliorativnymi sistemami [New technologies for design, construction justification, operation and management of reclamation systems] / In doctor of technical Sciences, Professor L. V. Kireycheva (ed). - Moscow, 2010. - 240 p.

11. Povyshenie otvetstvennosti sel'khoztovaroproizvoditeley za vosproizvodstvo poch- vennogo plodorodiya melioriruemykh zemel' [Increasing the responsibility of agricultural producers for the reproduction of soil fertility of reclaimed land] / G. T. Balakay, I. F. Yurchenko, E.A. Lentyaeva, G. Kh. Yalalova // Agrokhimicheskiy vestnik [Agrochemical Bulletin]. 2015. - Vol. 2. - №2. - Pp. 29-33.

12. Sannikova M.O., Yaroslavskiy V.A. Teoreticheskie osnovy protsessa otsenki riskov meliorativnykh investitsionnykh proektov [Theoretical foundations of the risk assessment process for reclamation investment projects] // Vestnik Saratovskogo gosudarstvennogo sotsial'noekonomicheskogo universiteta [Bulletin of the Saratov state socio-economic University]. 2012. — №5 (44). — Pp. 136-140.

13. Sposob provedeniya ekspluatatsionnogo monitoringa tekhnicheskogo sostoyaniya lotkovykh kanalov orositel'nykh sistem [Method for conducting operational monitoring of the technical condition of tray channels of irrigation systems]: pat. 2368730 Russian Federation: MPK E 02 B 13/00 / Volosukhin V.A., Bandurin M.A.; zayavitel' i patentoobladatel' Novocherk. gos. melior. akad. №2008100926/03, declared 09.01.08; publ. 12.09.08, Bul. №28. - 7 p.

14. Turmachev E.S. Metodicheskie problemy kolichestvennogo opredeleniya riskov investitsionnykh proektov [Methodological problems of quantifying the risks of investment projects]// Analiz effektivnosti investitsiy [Investment performance analysis]. — 2006. №3. - Pp. 45-58.

15. Yurchenko I.F. Metodologicheskie osnovy sozdaniya informatsionnoy sistemy upravleniya vodopol'zovaniem na oroshenii [Methodological bases of creating an information system for water use management in irrigation] // Vestnik rossiyskoy sel'skokhozyaystvennoy nauki [Bulletin of Russian agricultural science]. 2017. - №1. - Pp. 13-17.

16. Yurchenko I. F. Planovo-predupreditel'nye meropriyatiya povysheniya nadezhnosti meliorativnykh ob"ektov [Planned preventive measures to improve the reliability of reclamation facilities]// Prirodoobustroystvo [Environmental engineering]. — 2017. — №1. - Pp. 73-79.

17. Yurchenko I. F., Nosov A. K. Effektivnost' organizatsionno-pravovykh form ispol'zovaniya melioriruemykh zemel' [Efficiency of organizational and legal forms of use of reclaimed land]// 
Vestnik RASKhN [Bulletin of the RAAS]. 2012. - №6. - Pp. 10-12.

18. Risk assessment of land reclamation investment projects / I.F. Yurchenko, M.A. Bandurin, V.V. Vanzha and other // Advances in so- cial science, education and humanities research Proceedings of the International Conference Communicative Strategies of Information Society (CSIS 2018). - 2019. - Pp. 216-221.

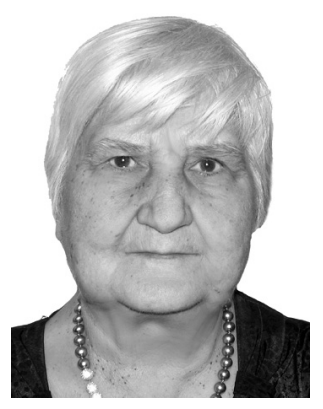

Юрченко Ирина Федоровна - доктор технических наук, доцент, главный научный сотрудник ФГБНУ «Всероссийский научно-исследовательский институт гидротехники и мелиорации имени А. Н. Костякова». Ведущий специалист в области информационных технологий поддержки управленческих решений в мелиоративной деятельности. Автор порядка 200 работ по проблемам развития мелиоративного водохозяйственного комплекса, обеспечения безопасности гидротехнических сооружений оросительных систем и оценки эффективности мелиоративных инвестиционных проектов.

Yurchenko Irina Fedorovna - Doctor of Engineering Sciences, Associate Professor, Chief Researcher, Federal State University «All-Russian Research Institute of Hydraulic Engineering and Land Reclamation named after A.N. Kostyakov». Leading specialist in the field of information technology management decision support in reclamation activities. Author of about 200 works on the problems of development of reclamation water management complex, ensuring the safety of hydraulic structures of irrigation systems and evaluating the effectiveness of land reclamation investment projects.

127550 , г. Москва, ул. Большая Академическая, 44 44 Bolshaya Academitcheskaya st., 127550, Moscow, Russia E-mail: irina.507@mail.ru 


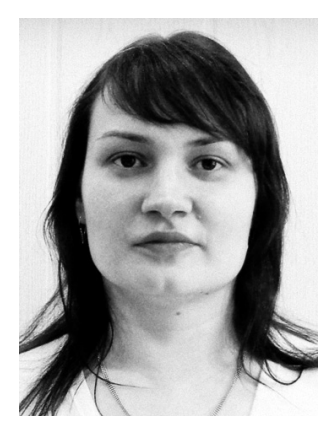

Бандурина Инна Петровна - кандидат социологических наук, доцент кафедры «Производственный и инновационный менеджмент» Южно-Российского государственного политехнического университета (НПИ) им. М.И. Платова. Автор работ по социально-экономическим аспектам природопользования, системам экологического мониторинга экономической деятельности производственных систем и экологическим неправительственным организациям.

Bandurina Inna Petrovna - Candidate of Sociological Sciences, Associate Professor, Department of Production and Innovation Management, Platov South Russian State Polytechnic University (NPI). Author of works on socio-economic aspects of environmental management, environmental monitoring systems of economic activity of production systems and environmental non-governmental organizations.

346428, г. Новочеркасск, ул. Просвещения, 132 132 Prosveshcheniya st., 346428, Novocherkassk, Russia E-mail: chepuraib@gmail.ru

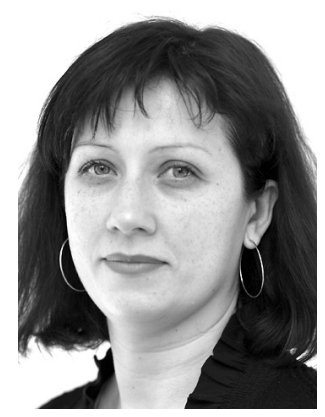

Сальникова Инна Ивановна - ассистент кафедры «Производственный и инновационный менеджмент» Южно-Российского государственного политехнического университета (НПИ) им. М.И. Платова. Автор работ по производственным системам, эффективности технологических процессов, методам управления обращения с отходами.

Salnikova Inna Ivanovna - Assistant, Department of Production and Innovation Management, Platov South Russian State Polytechnic University (NPI). Author of works on production systems, efficiency of technological processes, waste management methods.

346428 , г. Новочеркасск, ул. Просвещения, 132

132 Prosveshcheniya st., 346428, Novocherkassk, Russia

E-mail: s-inna79@mail.ru 